\title{
Chapter 7 \\ The Role of Social Finance in Resolving Regional Issues-Recent Trends in Japanese Civic Crowdfunding
}

Keywords Civic crowdfunding $\cdot$ Silver democracy $\cdot$ Project-based Hometown Tax

Donation $\cdot$ Resolving regional issues $\cdot$ Civic engagement

\subsection{From Municipality-Initiated to Civic Engagement}

This chapter explores the effective use of crowdfunding (CF) and Hometown Tax Donation in machizukuri and resolving regional issues. While the two are closely related, they differ slightly in terms of purpose of use, and thus, it is necessary to organize their respective characteristics and usability.

Historically, governmental bodies represented by municipalities would be expected to take a leading role in resolving regional issues; however, as symbolized by the frequent discussions surrounding "extinction of rural areas," regional economies have been contracting on the back of depopulation, an aging society with declining birth rate, and decline in local industries among other factors, and many municipalities are finding it difficult to secure ample revenue source. At the same time, the ratio of citizens aged 65 or older to Japan's total population is $28.4 \%$, one of the highest in the world (MIC 2019), leading to intensified "silver democracy" where seniors increasingly influence politics, and municipalities are therefore compelled to prioritize the silver generation when dealing with regional issues. Against this backdrop, there are high expectations for social finance to become a new revenue source for resolving regional issues.

$\mathrm{CF}$, introduced in the previous chapters, has been gaining much attention as a method of social finance. Unlike conventional investments or loans, funds are procured from "crowds." There are many cases of CF worldwide, and several CF platforms dedicated to regional projects have also been developed in Japan. Additionally,

This chapter is based on Hoda and Kubo (2019), with some edits and additions 
Japan deploys Hometown Tax Donation, a unique system that enables municipalities to procure funds. Hometown Tax Donation allows individuals to make donations to a municipality or municipalities of their choice. While attention is often centered on its gifts, the system was originally intended to generate new capital flow to rural areas. Below, I introduce cases where regional issues were resolved using CF and Hometown Tax Donation.

\subsubsection{Regional Issues that Cannot Be Dealt with as Desired}

The first case is of Osaka Women's and Children's Hospital, which is part of the Osaka Prefectural Hospital Organization. In 2017, they solicited donations through CF to purchase incubators for transporting newborn babies. They collected over 10 million yen, outstripping their target of 3 million yen, and were able to buy three incubators. Meanwhile, a Mainichi Newspapers article dated September 14, 2017 reported that "Numerous criticisms were made online, such as 'tax should be allocated with priority to such purchases'." Such online criticism was not targeted at the initiative itself, but at the fact that tax was not distributed to something as important as an incubator.

$\mathrm{CF}$ and Hometown Tax Donation are significant in that they uncover (i.e., make visible) social and regional issues. It is self-evident that the lack of incubators is a major issue for the region and society. However, municipalities with limited revenue source and human resource attend to social and regional issues by order of higher importance or priority. Why were funds and resources not directed toward these incubators? Who decides the priority of social and regional issues that need to be resolved? The local government and assembly do. The assembly is (or assembly members are) elected by local residents. And many voters are seniors. On top of the aging of society, there is a major gap between generations in voter turnout rate; therefore, assembly members, the assembly and municipality are compelled to prioritize issues related to the elderly. The incubator incident precisely depicts this. While no one would deny that the lack of incubators is a major issue, its priority is low because of the current social structure (of silver democracy).

When local governments attempt to resolve an issue, the required human resource or volume of paperwork is hardly different between a project (i.e., issue) worth 100 million yen and worth 1 million yen. Thus, the project (i.e., issue) worth 100 million yen is prioritized, leaving issues worth hundreds of thousands of yen or several million yen unattended. In the case above, one incubator costs 3 million yen, which is not a large amount. 


\subsubsection{Democratization in Securing Budgets Within a Local Government}

Next, I will introduce a case of Imabari City, Ehime Prefecture, which faced the issue of animal damage including by wild boar, and in response, procured funds through CF-style Hometown Tax Donation to finance the opening of Shikotsu Ramen Restaurant, which used wild boar bone for broth. The project, which aimed "to kill two birds with one stone" by resolving a regional issue on the one hand and producing a new local specialty on the other, successfully met its target of 4 million yen. The financing method of this project was proposed not by the city's Finance Department, but by the Regional Promotion Office. CF-style Hometown Tax Donations can be procured independently by respective departments.

Normally, when respective departments need funds, they draft a budget plan from the summer of the previous year and submit the plan to the planning and finance departments, at which point, they face the aforementioned problem of issue prioritization. While animal damage measures are undoubtedly important, its priority would be low and budget would not be allocated under ordinary circumstances. Even if budget were to be allocated, it would be largely discounted and only available one year later, which is unimaginably slow by private-sector standards. Since the project will start from there, it would take about two years to resolve the issue.

On the other hand, using Hometown Tax Donation or CF will drastically accelerate the process. Additionally, it will be possible to find those concerned with this issue from across Japan since funds are procured online. Moreover, information can be disseminated widely through SNS or other media. Such initiatives may even be covered by major media outlets. The largest "issue" for social and regional issues is garnering interest and awareness. In this respect, Hometown Tax Donation and CF are exceptional.

The fact that individual departments in local governments can now procure their own funds can be interpreted as democratization in securing budgets. Major issues for the minority or socially vulnerable would take forever to resolve under the current system where budgets are secured based on a majority-rule democracy. Both incubators and animal damage measures only required several million yen. The outcome of a 100-million-yen project would hardly be influenced by cutting back several million yen. In contrast, the impact of redirecting that several million yen toward an issue with no budget at all would be significant. Local governments are of course aware of this fact. However, they are unable to secure the resource, including personnel, that would be required if several million yen from a 100-million-yen project is redirected to a new purpose; hence, the 100-million-yen project is implemented as is.

The significance of Hometown Tax Donation and CF is that it sheds light on and solicits empathy for small social and regional issues. 


\subsection{Distinction in Features and Usage of CF and Hometown Tax Donation}

\subsubsection{Difference in Restrictions of Project Owners and Tax Benefits of Funders}

In principle, municipalities are the ones who procure funds in Hometown Tax Donation. On the other hand, CF can be implemented not only by municipalities but by anybody or any organization with the will, including companies, individuals and non-profit organizations (NPOs). The most distinct feature of Hometown Tax Donation's framework is that it can only be used by municipalities. Accordingly, funders' tax benefits also differ. Hometown Tax Donation is subject to cash back in the form of inhabitant tax credit and income tax return for any amount exceeding 2000 yen. In contrast, $\mathrm{CF}$ does not accompany tax benefits in most cases, and funders pay the entire amount out of their pockets. Although some cases of CF are subject to tax benefits, the amount is not as large as that of Hometown Tax Donation since benefits comprise deductions from income. Thus, in terms of actual out-of-pocket burden of funders, Hometown Tax Donations would be more economical.

\subsubsection{Effects on Project Owners}

By using the Hometown Tax Donation framework, individuals or organizations seeking to procure funds can benefit from endorsement by a municipality. Meanwhile, municipalities can save resource if local individuals, NPOs or companies procure funds and resolve regional issues through the Hometown Tax Donation framework. Accordingly, some municipalities have started accepting public applications for projects seeking to resolve regional issues using Hometown Tax Donation.

In such applications, municipality's assessment of the project and project owner becomes important. For example, Kobe City, Hyogo Prefecture, aided local incubation of private companies and individuals using the Hometown Tax Donation framework. They accepted applications from and assessed prospective businesses, and the accredited businesses were allowed to procure funds through a CF web portal. The accredited projects were introduced on the site as being subject to Hometown Tax Donation, and funders could receive the same tax benefits as that of Hometown Tax Donation. Similarly, Sumida Ward, Tokyo, deploys a CF-style Hometown Tax Donation titled "Sumida Dream Endorsement Project," and aids businesses implementing projects within the ward. In this way, private businesses can implement CF using the Hometown Tax Donation framework with an aim to resolve regional or social issues.

In contrast, $\mathrm{CF}$ alone can be used more flexibly relative to Hometown Tax Donation. Project owners can apply directly to $\mathrm{CF}$ web portals without going through municipal screening. It should be noted that since $\mathrm{CF}$ web portals also conduct 
screening, not all prospective projects end up being listed. However, while Hometown Tax Donation requires that projects serve to resolve regional issues, CF does not have such restrictions. Thus, projects can be designed more freely.

In summary, $\mathrm{CF}$ that does not depend on the Hometown Tax Donation framework is used to finance independent projects by individuals, companies and NPOs among other players, and its funders consist mostly of people associated to or close to the project owners; meanwhile, CF based on the Hometown Tax Donation framework undergoes public application and screening, and is used to resolve regional and social issues.

While projects that use the municipality-led Hometown Tax Donation framework are most definitely carried through since they are subject to public application and screening, the quality of projects listed on CF web portals are mixed since the hurdle for listing is lower. This implies that funders must assess the quality of projects themselves. In reality, there are cases where projects are not carried through as initially planned even after funds are secured through CF.

\subsection{Civic Crowdfunding}

Civic crowdfunding (CCF), which specializes in resolving community issues, is becoming widespread in the US and UK. A Japanese version of CCF is also gaining momentum, where funds are collected using the CF or Hometown Tax Donation frameworks to resolve regional issues (Japanese CCF). We explore the prospects and issues of such CCF below.

While CCF is a new type of CF, it differs from conventional CF in that funds are solicited from citizens to resolve community or social issues. CCF helps resolve wide-ranging regional issues, although its market size is not large, CCF helps resolve wide-ranging regional issues, including social, educational and cultural events, and is known to produce various public property (Charbit and Desmoulins 2017). This indicates that CCF offers a major opportunity for citizens, civic organizations and local governments to use funds for projects that benefit the public. CCF generates a flow of citizen's money to specific projects (Stiver et al. 2015), and is gaining attention as a prospective alternative revenue source amid the tightening of governmental budgets (Gray 2013).

According to a research conducted by Davies (2014) of 1224 CCF projects, based on data collected from seven CCF platforms in four countries between June 2012 and March 2014, 711 projects achieved their target amount. The average amount procured by all projects was 204.36 dollars, while the average amount procured by projects that achieved their target was 9502 dollars. Davies classified the projects into 15 categories. The analysis revealed that the largest portion of projects was "park and gardens" (one-fourth of all projects), followed by "events" and "education and training" (one-fourth of all projects, combined). CCF is being used to resolve issues related to local public properties, such as small gardens and parks in large cities, and tends to benefit those living in the local or neighboring communities. 
Meanwhile, it has been pointed out that natural disaster relief efforts are more likely to secure donors from both within and without a region (Charbit and Desmoulins 2017). In summary, CCF can be regarded as an effective financing method not only for resolving regional issues that benefit local residents but also for social issues such as poverty and national disasters.

\subsection{Recent Trends in Japanese CCF Using Hometown Tax Donation}

\subsubsection{Overview of Japanese CCF}

Japanese CCF mainly involves procuring funds in a manner similar to CF under the Hometown Tax Donation framework to conduct specific projects that resolve municipal issues. Trustbank, Inc., which operates a Hometown Tax Donation web portal, started Japanese CCF under the name "government crowdfunding (GCF)" in September 2013, and the same scheme is now being offered by other web portal providers as well, including, i-mobile Co., Ltd., under the name "Furunabi Crowdfunding" from April 2018, and Satofull Co., Ltd., a corporate member of SoftBank Group Corp., under the name "Satofull Crowdfunding" from May of the same year (Nihon Keizai Shimbun 2018).

Japanese CCF aims to resolve regional issues by designating specific projects as the usage of Hometown Tax Donations, and soliciting donations from empathizers across Japan. Even when the target amount is not reached, donations are not returned to donors, and projects are deployed according to procured amount, for example by extending the period or with municipal financial aid for the shortfall. While donors could previously only designate usage of donations by general categories such as "education," "welfare" or "industrial promotion," Japanese CCF enables donors to select and donate to specific projects. This is effective in "fostering tax payers' awareness toward tax," one of the original objectives of Hometown Tax Donation, and also offers citizens an opportunity to gain interest in social issues. In addition, it is easier to implement projects targeting the younger generation, those raising children, or the socially vulnerable, to which budgets are normally difficult to allocate in a silver democracy.

Adhikary et al. (2018) pointed out that Japanese CF differs from western CF, which is oriented toward short-term profits, in that it is based on relationship and tends to establish long-term relationships, suggesting that Japanese CF may produce benefits for communities and stakeholders. While recent trends in Japanese CCF are consistent with overall trends in Japanese CF, there is a high possibility that it will develop further going forward.

Japanese CCF enables taking speedy measures. Although obtaining consensus within the municipality requires some time, once a project is launched, funds can be procured immediately within a certain time frame, after which funds can be 
used immediately. Normally, budget planning requires adjustments by the strategy and finance department as well as approval by the assembly, whereas, in the case of Japanese CCF, the department that oversees the issue can take charge of financing and deploying the project. According to an interview with Imabari City, Ehime Prefecture, the reason they used Japanese CCF was because it enabled the department in charge to take ownership.

Additionally, since funds procured by Japanese CCF are additional revenue on the part of municipalities, it will be possible to avoid competitions for budget share within the municipality as well as the issue of prioritization among local problems. The negative aspects of a silver democracy can also be avoided. Another important point is that although municipal revenue will increase, this will not affect the amount of local allocation tax grants received by the municipality the following fiscal year, as would be the case with normal tax revenue, since donations are secured from outside the region.

\subsubsection{The Current Status of Japanese CCF}

According to data of Furusato Choice, a Hometown Tax Donation platform which deploys the most Japanese CCF projects, 445 projects were deployed as of May 20, 2019, among which 175 reached their target amount. It is noteworthy that Furusato Choice also deploys Japanese CCF based on wide-area collaboration. This is a system where multiple municipalities collaborate to solicit donations for issues common to municipalities across Japan. Such CCF is implemented based on the idea that collaboration by multiple municipalities should boost promotion of social issues and enable soliciting donations more effectively. In fact, while the rate of achieving target amounts for all Japanese CCF in Furusato Choice was 39.8\%, the same rate for Japanese CCF based on wide-area collaboration was higher at 55.1\% (as of May 2019).

Looking at the data more closely, in terms of number of Japanese CCF projects based on wide-area collaboration, incubation accounted for nearly half. This symbolizes the high expectation toward regional economic revitalization through producing local entrepreneurs. As for amount of funds procured, large amounts were collected by social issues such as disaster relief efforts, animal protection and child poverty. Average donation amount is largest for disaster relief, with all but one project achieving their target amount. Large amounts of funds are flowing to issues that draw extensive attention from society, such as natural disasters in rural areas, which is consistent with the finding by Charbit and Desmoulins (2017) regarding disaster relief support in CCF. 


\subsubsection{Using Japanese CCF for Disaster Relief}

The movement to donate through Japanese CCF for restoration of disastersincluding heavy rain, earthquakes and heavy snow, which occur year after year-has been gaining a foothold. Most recently, Japanese CCF has been used extensively to support healthcare workers and businesses affected by the novel coronavirus pandemic. Since the Hometown Tax Donation framework is used, donations are sent directly to the municipality without deductions such as for operating fees by intermediary organizations, and roughly the entire amount can be directed to affected areas (or people). The presence of Japanese CCF using the Hometown Tax Donation framework has likely helped donors excavate new disaster relief funds.

Also, an important factor in disaster relief is to not let memories fade and to report progress to supporters. Hometown Tax Donation web portals can help prevent the fading of memories and keep supporters informed, since such portals function as media and are visited repeatedly by donors. Relief efforts can be enhanced by posting information not only on donations but also on other necessary human or material support, such as volunteers or provision of supplies.

Furthermore, a scheme for delegated donations is also being established. This a scheme where other municipalities support a disaster-hit municipality that is too busy with reconstruction operations to handle reception of Hometown Tax Donations, by managing reception operations in their place. There are also new initiatives where unaffected municipalities donate $3 \%$ of the Hometown Tax Donations they received to the disaster-hit municipality. In this way, Japanese CCF can be used flexibly across the nation since a uniform Hometown Tax Donation system is adopted by municipalities throughout Japan. While there are various debates regarding the pros and cons of Hometown Tax Donations since many people donate mainly to receive gifts, the active use of Japanese CCF for disaster relief continues to be desired.

\subsection{Collaboration with Private Companies Using Japanese CCF}

\subsubsection{Projects that Succeeded by Creating a Consortium}

One characteristic of Japanese CCF is that some projects have been achieving greater levels of success by collaborating with private companies. For example, the "Children's Meal Delivery Project" targeting impoverished children and deployed by Bunkyo Ward in Tokyo using Japanese CCF collected donations largely exceeding their initial target; this success was achieved through collaboration among the municipality, an NPO, and a private company. More specifically, NPO Florence, which offers such services as sick child care, was the project owner, while the Bunkyo 
Ward municipality managed reception of donations, and LINE@ was used as a tool for communicating with families potentially in need of meal deliveries for their children.

Normally, if an NPO tries to procure funds and deliver meals to children, it will be difficult to yield intended outcomes because of disadvantage in terms of public trust. However, trust will rise drastically with municipal endorsement. At the same time, municipalities are not necessarily apt at promoting their efforts to the public or approaching residents who may need certain services. Thereby, the NPO proposed using LINE@ as a communication tool—something the municipality had never considered. This makes it easier both physically and psychologically to make inquiries about or apply to children's meal delivery, relative to conventional methods such as sending documents by post, calling, or submitting documents directly at the ward office.

In fact, the number of applications for meal deliveries significantly surpassed expectations owing largely to adopting LINE@. This led to the implementation of a second round. This case is elaborated in "2017 Regional Revitalization Using Crowdfunding Study Group Report” (Osaka Prefecture Municipal Development Foundation).

This children's meal delivery case succeeded because a consortium was created among various players including a municipality, NPO and private company.

\subsubsection{A Framework Where Local Issue Awareness and Active Individuals and Companies Back Up Municipalities}

Aside from the aforementioned case of Bunkyo Ward, a number of Japanese CCF have been deployed through collaboration among municipalities, private companies and NPOs, among others. Kamiyama Town, Tokushima Prefecture, deployed a project for developing new products using cedar with an aim to resolve the issue of reduced water retention of unlogged cedar plantations. Unnan City, Shimane Prefecture, deployed a project for institutionalizing community nurses-a progressive version of home-visiting nurses - in the region. This involved creating numerous locations within the region where patients could meet nurses, prompting a shift from medical care that waits for patients to visit hospitals, to preventive medical care that goes beyond the hospital walls. The introductory page of each project includes project details along with the "passion" of project owners, which arouses empathy. The more supporters, the more donations will be collected, enabling projects to be deployed.

Japanese CCF should advance further if motivated private companies and NPOs partner with municipalities that wish to enhance resident services but lack the resource and public messaging abilities. In fact, Saga Prefecture offers opportunities for NPOs not only within the prefecture but across Japan to resolve regional and social issues using Japanese CCF under the prefecture's Hometown Tax Donation 
scheme. Motivated NPOs will gain a reliable partner, while Saga Prefecture will be able to revitalize the region by attracting NPOs.

\subsection{Effects of Japanese CCF on Machizukuri}

One positive side effect of Japanese CCF is that it offers municipalities an opportunity to think about machizukuri. Although the Hometown Tax Donation scheme is used to procure funds, in the case of normal Hometown Tax Donation, municipalities will first focus on procuring funds and think of their usage later; thus, they will be engrossed in procuring attractive gifts. Once donations are collected, municipalities will set them aside and mull over their usage. In due course, departments within the municipality will start saying they want to use donations to supplement general revenue, and while attending to each demand, donations - collected with much effort but used for numerous, inexplicit purposes-will disperse into thin air. Or local residents may complain that they "are not benefitting from Hometown Tax Donations," whereby, the municipality may end up building a tangible, visible hakomono (i.e., public building). There have been countless cases in the past where municipalities ended up suffering from massive maintenance expenses thereafter.

On the other hand, when using Japanese CCF, specific usage of funds is determined beforehand, and hence, important prospective issues of the region will be unearthed in advance. Also, since funds are sourced from outside the region, it is easier to spend funds not only on local residents but for external purposes, such as promoting migrations or attracting satellite offices and venture businesses. Municipal administration thus far has relatively been confined to cutting back on public works in response to reduced revenues or to cut expenses, and money was hardly ever used strategically, nor was deliberation extended to future-oriented machizukuri. On the other hand, implementing Japanese CCF requires a shift toward positive thinking, thereby offering municipalities an opportunity to contemplate machizukuri. Additionally, by offering opportunities to collaborate with companies and NPOs, Japanese CCF may lead to more dynamic ideas for increasing associating populations. Moreover, while regions rich in primary products tend to be of advantage in regular Hometown Tax Donation, with CCF, urban areas are not disadvantaged, as seen in the case of Bunkyo Ward, Tokyo. 


\subsection{Potential Issues of Japanese CCF}

\subsubsection{Possibility that Unappealing Projects Have Higher Local Demands}

When implementing Japanese CCF, explicitness and comprehensibility of projects are important in successfully procuring funds, since funders are non-locals. One issue that will arise in this respect is whether non-locals would understand what the truly important issues are in that region. Even if a certain issue is important for the region, it may not gain much support from non-locals if it is indistinct and therefore unappealing. This may ultimately cause a competition in the CCF market to achieve higher levels of uniqueness. For example, which would attract more attention: a project for sewerage development in a specific rural area or for road-side flower-planting in view of the Tokyo Olympic and Paralympic Games? How about in comparison with projects that are easier for people to empathize with, such as culling of dogs, medical treatment, or poverty measures? All such issues which seek to be resolved through Japanese CCF are important for the region and society. However, since competition among projects is unavoidable, projects may end up placing excessive emphasis on uniqueness and conspicuousness, or on trying to generate empathy. For now, such concerns prove unfounded; yet close attention is required going forward as this is a potential issue.

\subsubsection{Regional Issues Versus Social Issues}

Another concern is the distinction between regional and social issues. Since Hometown Tax Donations are made to specific regions, there is not much resistance in using the money to resolve regional issues. However, when resolving social issues that are not specific to the region (e.g., treatment for intractable diseases), locals may question why that issue needs to be dealt with by their municipality, or why it is not addressed by the central government. Regarding this matter, rather than throwing cold water on Japanese CCF by debating the distinction between regional and social issues, it is better to first allow Japanese CCF to take root in society, uncover various regional and social issues, and then contemplate what revenue source and method should be used to resolve each issue.

\subsubsection{Pros and Cons of Municipal Involvement}

This holds true to Hometown Tax Donation in general, but it is necessary to be able to explain why projects need to be deployed by a municipality. Also, since trust of the general public toward the project will rise if the municipality is a project 
member, influence peddling must be avoided especially when collaborating with private companies or external organizations. At this stage, however, it is probably better to prioritize promoting public-private partnerships, which are finally taking shape, since municipal administration thus far tended to be oversensitive about profitsharing in collaborations with private companies or external organizations, and was therefore unable to take flexible actions toward resolving regional issues.

Municipal involvement is a must in Japanese CCF deployed under the Hometown Tax Donation scheme, and therefore, burden will be imposed on municipalities. Thus, the viability of Japanese CCF in a certain municipality will depend on whether or not there are motivated municipal staff.

Also, donors benefit from tax returns in Japanese CCF discussed thus far, since it is a form of Hometown Tax Donation; however, receiving tax benefits is difficult if the same project is deployed using regular CF. Going forward, the presence of Japanese CCF could possibly hinder the spread of regular CF projects that aim to resolve regional issues. Regarding this aspect, the next section examines Japanese $\mathrm{CCF}$ that is implemented as regular $\mathrm{CF}$.

\subsection{Japanese CCF Implemented Through a Regular CF Platform}

Japanese CCF discussed thus far requires municipal involvement since it uses the Hometown Tax Donation framework. However, at times, it may be better to deploy CCF based on the regular CF scheme rather than the Hometown Tax Donation scheme; for example, when trying to resolve regional or social issues that are not fit for municipal engagement, or when flexibility will be lost by municipal interference. Although CCF based on regular CF will be inferior in terms of aforementioned tax benefits, it is more convenient in the sense that motivated individuals, organizations or companies are given more discretion when launching projects.

READYFOR, Inc., a leading CF web portal provider, handles many projects in this field. Especially in 2020, many projects were launched in support of healthcare workers fighting against and businesses affected by the novel coronavirus. When in need of urgent support, as in the case of the novel coronavirus pandemic, needs may be better met through independent deployment of CCF by individuals or companies. Also, more flexibility will be allowed when restricting support to specific region or people, since the issue of municipal accountability can be avoided without their involvement.

I analyzed 65 projects that had procured the largest funds up till June 2020 on the READYFOR platform, and 24 were donation-based, while 41 were purchasebased. Yet, among the 41 purchase-based projects, only one was for product development, with the rest consisting mostly of projects for organizing community events or creating a hot spot for medical, welfare or educational purposes. In other words, purchase-based projects on READYFOR mainly consisted of projects for engaging 
in the local community. The funder base sought by venture businesses or SMEs that want to deploy purchase-based CF to develop products or businesses, and the funder base using READYFOR is likely different; therefore, projects that fall under so-called CCF are highly compatible with READYFOR.

Among the 65 projects, 22 were for medical support (including 8 for cancer treatment research, and 5 for supporting university research in other fields), while 5 were implemented by local chambers of commerce and industry. Medical support is more of a social issue than a region-specific issue of a single municipality, and requires support that extends beyond municipal boundaries. Therefore, it may be less convenient to use CCF through Hometown Tax Donation in which municipal boundaries are a given. On the other hand, projects implemented by chambers of commerce and industry were mainly for supporting local restaurants whose revenues were dented by the pandemic; if the municipality were to provide such support, it could face difficulty explaining to the public why support is restricted to restaurants. Hence, CCF through Hometown Tax Donation may also not be suitable when support is restricted to certain targets.

As such, it may be possible to distinguish the use of CCF through Hometown Tax Donation and through regular CF by applying the former to regional issues that municipalities acknowledge need to be resolved, while applying the latter to more widespread social issues. The hurdle for deployment is likely higher when using Hometown Tax Donation since funds will be sourced from tax. CCF based on regular $\mathrm{CF}$ may function as an alternative means for clearing this hurdle.

\subsection{Summary: Toward Further Advancement of Japanese CCF}

This chapter discussed the prospects of resolving regional issues with civic participation using CCF. Both schemes of Hometown Tax Donation and CF may be used. Such CCF is significant since it not only allows financing but also plays a major role in uncovering regional and social issues, and is also effective in medical care or disaster relief support. Moreover, it serves to democratize the process of securing budgets for resolving such issues.

Under a silver democracy, CCF may be leveraged further as a means to resolve the issue of regional revitalization. Since such CCF is still at its early stage, detailed analysis remains to be done, and studies must be accumulated from various perspectives, which may include impact of CCF donors' attributes and municipality size on donation amount, or outcomes of projects.

Also, with regards to potential improvements of the system, it may be necessary to consider offering tax benefits, similar to that of Hometown Tax Donation, for CCF that resolves regional issues outside the Hometown Tax Donation framework. 


\section{References}

Adhikary BK, Kutusna K, Hoda T (2018) Crowdfunding: lessons from Japan's approach, Springer briefs in economics. Kobe University social science re-search series.

Charbit C, Desmoulins G (2017) Civic crowdfunding: a collective option for local public goods? OECD regional development working papers

Davies R (2014) Civic crowdfunding: participatory communities, entrepreneurs and the political economy of place. MSc thesis, Massachusetts Institute of Technology, Cambridge, MA

Gray K (2013) Built by the crowd: the changing world of public infrastructure. Wired UK, 4 November. Available at: https://www.wired.co.uk/article/built-by-the-crowd (Cited 25 May 2019)

Hoda T, Kubo Y (2019) Recent trends in social finance for resolving regional issues-Japanese civic crowdfunding (In Japanese). J Econ Bus Admin 220(4):67-76

Nihon Keizai Shimbun (2018) New endorsement: crowdfunding-style in Hometown Tax Donation (In Japanese). November 17, 2018 Nihon Keizai Shimbun Morning Paper

Stiver A, Barroca L, Minocha S, Richards M, Roberts D (2015) Civic crowd-funding research: challenges, opportunities, and future agenda. New Media Soc 17(2):249-271

Open Access This chapter is licensed under the terms of the Creative Commons AttributionNonCommercial-NoDerivatives 4.0 International License (http://creativecommons.org/licenses/bync-nd/4.0/), which permits any noncommercial use, sharing, distribution and reproduction in any medium or format, as long as you give appropriate credit to the original author(s) and the source, provide a link to the Creative Commons license and indicate if you modified the licensed material. You do not have permission under this license to share adapted material derived from this chapter or parts of it.

The images or other third party material in this chapter are included in the chapter's Creative Commons license, unless indicated otherwise in a credit line to the material. If material is not included in the chapter's Creative Commons license and your intended use is not permitted by statutory regulation or exceeds the permitted use, you will need to obtain permission directly from the copyright holder.

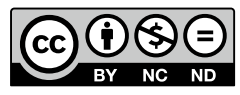

